\title{
Introduction: Managing Patients With Chronic Angina: Emerging Therapeutic Options for Improving Clinical Efficacy and Outcomes
}

JOHN S. RUMSFELD, MD, PhD, FACC

\section{TARGET AUDIENCE}

Managed care pharmacists and other health care practitioners

\section{LEARNING OBJECTIVES}

Upon completion of this program, participants will be better able to

1. describe the epidemiology, impact, pathogenesis, patient presentation, and treatment of stable angina;

2. compare and contrast the pharmacology and pharmacodynamics of ranolazine with that of other antianginal drug therapies, discuss the approved uses and pharmacokinetics of ranolazine, summarize the results of clinical studies of the efficacy of ranolazine for the treatment of chronic angina, and name a safety concern associated with the use of ranolazine;

3. estimate the direct and indirect costs of chronic stable angina in the United States and identify the largest components of the direct costs of narrowly defined chronic angina and coronary artery disease; and

4. describe recent trends in the use of coronary revascularization in the United States and compare and contrast the initial and long-term costs and clinical outcomes from percutaneous coronary intervention, coronary artery bypass grafting, and medical management in patients with stable angina.

J Manag Care Pharm. 2006;12(8):S2-S3

\section{Author}

JOHN S. RUMSFELD, MD, PhD, FACC, is a staff cardiologist and cardiovascular outcomes researcher, Denver VA Medical Center, and an associate professor of medicine, University of Colorado Health Sciences Center, Denver.

AUTHOR CORRESPONDENCE: John S. Rumsfeld, MD, PhD, FACC, Staff Cardiologist and Cardiovascular Outcomes Researcher, Denver VA Medical Center, 1055 Clermont St., Denver, CO 80220. Tel: (303) 370-7575; Fax: (303)370-7580; Email: john.rumsfeld@va.gov.

Copyright $\odot$ 2006, Academy of Managed Care Pharmacy. All rights reserved.
C oronary heart disease (CHD) remains the leading cause of death among American men and women. ${ }^{1}$ However, advances in the treatment of acute coronary syndrome and an increasing number of therapies to reduce recurrent cardiac events have led to more patients surviving with chronic CHD. The primary symptom of chronic CHD is angina (chest pain on exertion or under mental or emotional stress). ${ }^{2}$

More than 6.5 million Americans suffer from angina, and the prevalence will continue to grow as patients live longer with CHD and as the population ages. ${ }^{1,2}$ Angina can severely limit patients functional status and diminish their quality of life. ${ }^{3,4}$ Patients with angina are less satisfied with their care. ${ }^{5}$ Moreover, angina is predictive of subsequent acute coronary syndrome and death among CHD outpatients. ${ }^{6}$ Given its prevalence and impact on health, chronic angina should not be treated as a benign condition and deserves increased attention from health care practitioners.

While angina is treatable through a range of pharmacologic treatments as well as coronary revascularization, ${ }^{2}$ it is often inadequately treated in clinical practice. ${ }^{7-10}$ For example, outpatients with chronic angina report a median frequency of 2 episodes/week, and the majority of these patients perceive their health as "fair" or "poor." ${ }^{10}$ There is also a misperception that angina is largely obviated in an era of coronary stenting and early invasive therapy for acute coronary syndrome. Yet, more than one quarter of patients have some angina 1 month after discharge for acute myocardial infarction, ${ }^{11}$ and one third of patients report daily to weekly angina 7 months after admission to the hospital for treatment of acute coronary syndrome. ${ }^{12}$ Ultimately, many CHD patients are left with varying degrees of residual angina despite treatment. This has provided the impetus to develop new pharmacologic therapies to better manage chronic angina.

The first article in this supplement describes the epidemiology, pathogenesis, and treatment of chronic angina, including the use of vasculoprotective and antianginal drug therapies and coronary revascularization procedures. The approved uses, pharmacology, pharmacodynamics, pharmacokinetics, efficacy, safety, and place in therapy of ranolazine-the first new antianginal drug therapy introduced in more than 20 years for the treatment of chronic angina - are addressed in detail in the second article. In the third article, the economic burden of chronic angina in the United States is quantified, and recent trends in the use of coronary revascularization are characterized. The clinical outcomes from and longterm costs of percutaneous coronary intervention, coronary artery bypass grafting, and medical management are compared in patients with chronic angina.

\section{DISCLOSURES}

This article is based on a presentation given by the author at a symposium titled "Emerging Therapies for Management of Patients with Stable Angina: 
Focus on Clinical Efficacy and Outcomes" at the Academy of Managed Care Pharmacy's 18th Annual Meeting and Showcase in Seattle, Washington, on April 5, 2006. The symposium was supported through an educational grant from CV Therapeutics, Inc. The author received an honorarium from CV Therapeutics, Inc. for participation in the symposium. He is a consultant for CV Therapeutics, Inc.

\section{REFERENCES}

1. Thom T, Haase N, Rosamond W, et al. Heart disease and stroke statistics2006 update: a report from the American Heart Association Statistics Committee and Stroke Statistics Subcommittee. Circulation. 2006; 113:e85e151. Available at: http://circ.ahajournals.org/cgi/content/abstract/ CIRCULATIONAHA.105.171600vl. Accessed April 7, 2006.

2. Gibbons RJ, Abrams J, Chatterjee K, et al. ACC/AHA 2002 guideline update for the management of patients with chronic stable angina: a report of the American College of Cardiology/American Heart Association Task Force on Practice Guidelines (Committee to Update the 1999 Guidelines for the Management of Patients With Chronic Stable Angina). Available at: http://www.americanheart.org/downloadable/heart/ 1044991838085 StableAnginaNewFigs.pdf. Accessed April 7, 2006.

3. Kim J, Henderson RA, Pocock SJ, et al. Health-related quality of life after interventional or conservative strategy in patients with unstable angina or non-ST-segment elevation myocardial infarction: one-year results of the third Randomized Intervention Trial of unstable Angina (RITA-3). J Am Coll Cardiol. 2005;45:221-28.

4. Dougherty CM, Dewhurst T, Nichol WP, et al. Comparison of three quality of life instruments in stable angina pectoris: Seattle Angina Questionnaire, Short Form Health Survey (SF-36), and Quality of Life Index-Cardiac Version III. J Clin Epidemiol. 1998;51:569-75.
5. Beinart SC, Sales AE, Spertus JA, et al. Impact of angina burden and other factors on treatment satisfaction after acute coronary syndromes. Am Heart J. 2003; 146:646-52.

6. Spertus JA, Jones P, McDonell M, et al. Health status predicts long-term outcome in outpatients with coronary disease. Circulation. 2002;106:43-49.

7. Carasso S, Markiewicz W. Medical treatment of patients with stable angina pectoris referred for coronary angiography: failure of treatment or failure to treat. Clin Cardiol. 2002;25:436-41.

8. Beaulieu MD, Blais R, Jacques A, et al. Are patients suffering from stable angina receiving optimal medical treatment? QJM. 2001;94:301-08.

9. Wiest FC, Bryson CL, Burman M, et al. Suboptimal pharmacotherapeutic management of chronic stable angina in the primary care setting. Am J Med. 2004;117:234-41.

10. Pepine CJ, Abrams J, Marks RG, et al. Characteristics of a contemporary population with angina pectoris. TIDES Investigators. Am J Cardiol. 1994; 74:226-31

11. Spertus JA, Krumholz HM, Reid K, et al. Predictors of angina after acute myocardial infarction: insights from the PREMIER Study. Am J Cardiol. 2006 In press.

12. Rumsfeld JS, Magid DJ, Sales AE, et al. History of depression, angina, and quality of life following acute coronary syndromes. Am Heart J. 2003;145: 493-99. 